\title{
Fertile Imaginations: an inner city allotment group
}

\author{
Joanna Seller, Jon Fieldhouse and Michael Phelan
}

Engaging people with mental illness in horticultural activities is nothing new. Asylums encouraged patients to work on farms, in orchards and in kitchen gardens. This activity gradually became distilled, formalised and applied clinically as 'moral treatment', out of which occupational therapy evolved (Paterson, 1997). 'Fertile Imaginations' is an attempt to offer horticultural activities to people with mental illness, within the framework of an inner city community mental health team (CMHT) and to ensure that the activities that engaged and benefited patients in the past, are not now denied.

Underlying occupational therapy is the principle that people need to be actively engaged in purposeful behaviour to remain healthy. This engagement or 'occupation' is seen as a route towards the satisfaction of the whole hierarchy of human needs from basic survival to higher cognitive and aesthetic needs, and self-actualisation (Maslow, 1968). Since occupation can shape health in this way it can also be a means of restoring or maintaining health, and this 'occupational therapy' works best when it embodies the characteristics of true human occupation: purposefulness, challenge, accomplishment and satisfaction. Two years' experience of the allotment project suggests that it has these in abundance. This paper looks at the aims of this inner city allotment group, and the way in which. and the extent to which, these aims are being met.

\section{Primary aims of project}

(a) Development of work-related skills, social skills and general functioning.

(b) General social support and contact with wider social networks. The social networks of people with schizophrenia are often very narrow and mediated by someone other than the sufferer. This can reinforce habits of social withdrawal and deficits in selfhelp (Brewer et al, 1994).

(c) Diversifying support into 'non-mental health' agencies enabling attenders to avoid the potential 'ghetto-isation' of mental health day care (Bryant, 1995).

(d) Relapse prevention, through integration into wider social networks and engagement in activity and accomplishment away from home environments which may be characterised by high levels of expressed emotion.

In addition the project allows staff to informally monitor the mental state of those attending, and act quickly when there are signs of relapse.

The project was started with an application to the Leisure Services Department of Hammersmith and Fulham Council requesting an allotment, detailing the project, and its aims, along with an assurance that the group would always be supervised by at least one qualified mental health worker. There was a two-year waiting list for an allotment, but the council allowed the group to bypass this and they were allocated a plot costing $£ 10$ a year. It was necessary to clarify the Trust's Health and Safety guidelines, as they applied to a non-trust site, to ensure staff were covered. Staff do not work singly and take a mobile phone to the allotment. Initial outlay for tools, materials and lockable storage space at the plot was £285.

Over two years, 41 referrals have been received, and 27 have attended an initial assessment. Of these, 15 became regular attenders (attending for more than three months), and four have attended for more than 18 months. Of the regular attenders, nine have schizophrenia and six have depression, 11 are male. Two of the regular attenders have applied for their own allotments. After leaving the group two have gone into open employment, one has started attending adult education classes and one has joined a supported work scheme.

Fertile Imaginations (a name chosen by the service users themselves) meets once a week for three hours. The group is facilitated by two occupational therapists, or one occupational therapist and a support worker. Apart from the obvious benefits of a community-based venue, a secondary aim was to positively contribute to the community which the CMHT serves, challenging misconceptions about mental illness and care in 
the community. The group provides its own social milieu, but also there is communication with other allotment holders who have been very positive and helpful, sharing tips, cuttings and conversation. The Council leased the group another plot for them to develop as the first plot had been so successful.

Fertile Imaginations offers a rich diversity of activities - physical work, abstract thought and planning, clerical tasks, social contact through a shared experience, and group outings. The range of tasks available allows people with differing abilities to be accommodated, including those who are physically less able. All activities carry intrinsically the potential for cognitive reframing; service users' experimentation with different roles (both macro roles such as 'worker' and micro roles such as 'minute-taker' in meetings, or even 'tea-pourer' during tea breaks); and reality orientation through exposure to natural living objects and processes (e.g. plants, the seasons, the weather). Other benefits include: encouraging healthy eating, free food (service users are free to take as much of the produce home as they wish) and a sense of pride in producing something.

Participation in the group opens up other avenues. One member of the group went as a representative to a similar project in Oxford and the project is making links with a MIND work rehabilitation project to create a joint working party to do small landscape gardening jobs for which service users will be able to get 'therapeutic earnings'. There was also a trip to Kew Gardens which was much enjoyed. The group holds planning meetings every season, and members can attend the Annual General Meeting of the Leisure Gardens Association.

But how is tending parsnips and building compost containers relevant to schizophrenia or bipolar affective disorder? The link is clear if we shift our focus from pathology to the kind of functional problems that service users present with (e.g. vulnerability to stress, cognitive difficulties, problems in relating to others and demotivation); particularly if one considers these in the light of Kielhofner's Model of Human Occupation (Kielhofner, 1985) which underpins the project. The model conceptualises the individual as an open system characterised by an ongoing interaction with the external environment, and an ability to maintain and change itself through this. People with severe mental illness have characteristically 'brittle' systems that have little flexibility to accommodate change - prompting crises.

The human system tends to be 'self-righting' given the right conditions and consequently the therapy on the allotment arises from service users being enabled to identify, mobilise and reinforce their own skills, strengths and resources through the tasks they engage in, and the milieu in which this takes place. Kielhofner (1997) emphasise the importance of 'tasks' in terms of dynamic systems theory. In other words, adaptive functioning relies not just on interpersonal characteristics but on the coming together of the person, the environment and the task in hand. It is the spontaneous, improvisational nature of 'doing' that draws people to try things out and ultimately add new skills to their repertoire, or become reacquainted with lost skills.

\section{Further developments}

An evaluation of the project has begun, with plans to introduce assessments on entry to the group and at various points during participation. A small evaluation of service user satisfaction with the project has already been undertaken. Group members were given a satisfaction questionnaire by the CMHT's research assistant away from the group setting. The main areas that service users liked about the allotment group were:

(a) A chance to get out of the house and do something.

(b) A chance to meet people and make friends.

(c) Taking home fresh vegetables.

(d) Being in the open air.

Service users were also asked how the group had helped them in other areas of their lives, and reported four main domains:

(a) Communication with others.

(b) Learning practical skills/teamwork/planning.

(c) Self-confidence.

(d) Helps concentration.

Preliminary evaluation of the group has found member satisfaction high, and self-organised rotas for watering the plots during the summer reflect the commitment some service users are prepared to make. It has been run successfully in an inner city area with high levels of deprivation, and can be easily generalised to other teams in other areas. The group was boosted when it won an award in the "Most Improved Plot' category which was presented to one of the members at the Allotment Holders Summer Barbecue. It will be interesting over the coming months to evaluate the group in more detail to assess its impact on the areas it aims to improve.

A Mental Health Network is coordinated by Horticultural Therapy, a national organisation. For further information please contact: Val George, Horticultural Therapy, Goulds Ground, 
Vallis Way, Frome, Somerset BAl1 3DN (Telephone: 01373 464782).

\section{References}

Brewer, P., Gadsden, V. \& Scrimshaw, K. (1994) The community group network in mental health: a model for social support and community integration. British Journal of Occupational Therapy, 57, 467-470.

BRYANT, W. (1995) The social contact group: an example of long-term group work in community mental health care. British Journal of Occupational Therapy, 58, 214-218.

KIELHOFER, G. (1985) A Model of Human Occupation: Theory and Application. Baltimore, MD: Williams and Wilkins.

- \& FORSYTH, K. (1997) The model of human occupation: an overview of current concepts. British Journal of Occupational Therapy, 60, 103-110.
MASLOW, A. H. (1968) Towards a Psychology of Being. New York: Van Nostrand.

PATERSON, C. F. (1997) Rationales for the use of occupation in the 19th century asylums. British Journal of Occupational Therapy, 60, 179-182.

Joanna Seller, Research Assistant, Jon Fieldhouse, Senior Occupational Therapist, and *Michael Phelan Consultant Psychiatrist, Area 2 Community Mental Health Team, Riverside Mental Health Trust, Gloucester House, $194 \mathrm{Ham}$ mersmith Road, Hammersmith, London W6 8BS

*Correspondence 